\title{
Assessment from Infrared Thermograms of Nitrogen Status in Rice Plants as Affected by Air Temperature
}

\author{
Chwen-Ming YANG \\ Division of Agronomy, Taiwan Agricultural Research Institute, Wufeng, Taichung Hsien 413, Taiwan
}

\begin{abstract}
Rice plants (Oryza sativa L. cv. TNG 67) were grown in the second cropping season of 2002 and the first cropping season of 2003 and infrared thermograms were taken by a thermal infrared imaging system. In Taiwan, air temperature, irradiance, and sunshine hour generally increased from lower to higher values following plant development in the First Crop, and vice-versa in the Second Crop. Canopy radiant temperature corresponded to changes of ambient air temperature during the growing periods and this cause-effect relationship affected the trend of temperature differences between ambient air and canopy as plants developed. However, such temperature differences were decreased by the increasing of air temperature in the First Crop and were decreased by the decreasing of air temperature in the Second Crop. There was a tendency that temperature difference increased with the increasing rates of nitrogen fertilizer in both crops, yet no such clear gradient was found near harvest. When further analyzing temperature difference distributions of rice plants treated with different rates of nitrogen, results indicated that, except near harvest, plants treated with higher nitrogen rates generally showed higher levels of temperature difference distribution and the phenomenon may be used as an indication of plant nitrogen status assessment in the first place.
\end{abstract}

Key words: Ambient air temperature, Canopy radiant temperature, Infrared thermogram, Nitrogen status, Rice

\section{Introduction}

Many plant species are thermoperiodic, that is, their growth behavior is influenced by the oscillation of diurnal temperature (Berry \& Raison, 1981; Ellis et al., 1992; Hodges, 1991; Robertson, 1968). Generally plants grow faster in a warmer daytime temperature than a cooler nighttime temperature. For a plant population, changes of canopy temperature are governed by both microclimate and soil environment. It is very common to observe a change of canopy temperature when plants encounter environmental impacts. Thus, plants from well-watered soil receive sufficient moisture through roots and have cooler leaves than those from arid environments (Clarke, 1997). In the water-limited soil or in excess transpiration, high temperature coupled with low humidity during daytime may cause an elevation of canopy temperature, while chilly nighttime temperature during cooler seasons results in a reduction of canopy temperature. Accordingly, temperature fluctuation of a plant canopy signifies whether or not plants are under stress conditions and monitoring of canopy temperature provides valuable information in determining the transition from no stress to an economically harmful level and hence water management practices (Hatfield, 1990; Jackson et al., 1977; Throssell et al., 1987).

Plant characteristics such as plant height (Went, 1944; Viglierhio \& Went, 1957) and leaf size and orientation (Erwin \& Heins, 1985; Fischer, 1954) are known to follow the rhythm of diurnal changes in temperature. Reports indicated that dry matter production in corn is closely correlated with temperature change and hence affects leaf initiation and elongation (Duncan \& Hesketh, 1968; Tollenaar et al., 1979; Watts, 1971). Growth symptoms such as seed germination (Lee et al., 1996), plant height (Su et al., 1997), flower opening, seed number and size, and pod formation (Thomas \& Raper, 1978; Thomas et al., 1981) in soybean are demonstrated sensitive to temperature. Leaf growth and plant development in rice plants are proven temperature dependent (Ellis $e t$ al., 1993; Yang \& Heilman, 1990; Yin et al., 1995) and yield production is found related to heat summation during the growing period (Yang, 1994).

Surface temperature of the plant canopy (vegetation) is a key factor not only for assessing heat fluxes at the canopy-atmosphere interface but also for evaluating growth status of a crop. Proper estimation of surface temperature is, therefore, of great importance in accurately estimating water and energy balance at the interface (Kustas, 1990; Seguin \& Itier, 1983 ) and fairly concluding growth performance (Su et al., 1997; Yang \& Heilman, 1990). Remote measurements of surface temperature using a thermal infrared radiometer are widely applied and are currently practiced nowadays, either on a field, regional or global scale (Yang, 1997). By the remote sensing technique, radiometric (radiative) rather than dynamic temperature can be determined (Su \& Yang, 1998; Yang, 1998), and both horizontal and vertical distributions of canopy temperatures may be modeled (Yang, 2003), with which the correlations between morphological-physiological processes and environmental factors can be evaluated.

This study was to assess nitrogen status in rice plants from canopy radiant (radiometric) temperatures extracted from infrared thermograms during growing periods and to evaluate ambient air temperature effects on canopy radiant temperatures under the influence of plant nitrogen status using the thermal infrared imagery technique.

\section{Materials and Methods}

Field experiments were conducted in the experimental farm $\left(24^{\circ} 45^{\prime} \mathrm{N}, 120^{\circ} 54^{\prime} \mathrm{E}\right.$, elevation of $85 \mathrm{~m}$ ) of the Taiwan Agricultural Research Institute (Wufeng, Taiwan) in the second cropping season of

Accepted on December 1, 2004 
2002 and the first cropping season of 2003. Rice plants (Oryza sativa L.) of cultivar TNG 67 were grown in a north-south direction in a density of 180,000 hills ha $^{-1}$, with a plant distance of $0.18 \mathrm{~m}$ and row spacings of $0.3 \mathrm{~m}$. The experimental plot was split up into subplots, which were $8 \mathrm{~m}$ in width and $50 \mathrm{~m}$ in length with a total area of $400 \mathrm{~m}^{2}$ per subplot. The soil was a loam soil (Fluvaquentic Dystrochrept) with $\mathrm{pH} 5.7$ and organic matter $1.2 \%$. The soil sampled before transplanting had Kjeldahl-N 755 ppm, available-P $9.5 \mathrm{ppm}$, exchangeable K $44.3 \mathrm{ppm}$, exchangeable $\mathrm{Ca} 623 \mathrm{ppm}$, and exchangeable $\mathrm{Mg} 107$ $\mathrm{ppm}$. Six levels of nitrogen (N) fertilizer, from $0(\mathrm{CK})$ to $150 \mathrm{~kg} \mathrm{ha}^{-1}$ with $30 \mathrm{~kg} \mathrm{ha}^{-1}$ intervals, were applied to produce variable growth rates and plant $\mathrm{N}$ contents. For each quantity, $\mathrm{N}$ fertilizer was divided into 3 equivalent amounts. The basal dose, using composite fertilizer Tai-Fei 39 (granule, $\mathrm{N}: \mathrm{P}_{2} \mathrm{O}_{5}: \mathrm{K}_{2} \mathrm{O}=12 \%$ : 18\%: 12\%, Taiwan Fertilizer Company, Kaohsiung), was applied at one week after transplanting. Ammonium sulphate (21\% granule, TFC) was applied at 2 weeks (Second Crop) or 3 weeks (First Crop) after transplanting as the second dose. Two weeks (Second Crop) or 3 weeks (First Crop) before heading, ammonium sulfate was applied as the last dose. To reduce weeds and pest infestations, pesticides were applied as needed according to the Plant Protection Manual (2000). Plants were irrigated regularly to avoid moisture stress.

To measure canopy radiant temperatures of different nitrogen treatments, a field-portable thermal infrared imaging system (ThermaCAM SC2000, FLIR Systems AB, Sweden) with a spectral range of 7.5-13 $\mu \mathrm{m}$ was used. Canopy temperatures' variation and distribution during growing periods and their differences to ambient air temperatures were analyzed. Thermograms (thermal infrared images) of the rice canopy were remotely taken from the border of subplots and the distance to the image center from the instrument was ca. $4 \mathrm{~m}$ in a viewing angle of ca. $30^{\circ}$. The measuring system includes a scanner with a $4 \mathrm{X}$ electromagnetic lens, which has a field-of-view $(\mathrm{F} \times \mathrm{V})$ of $24^{\circ} \times 18^{\circ}$, main body with $\mathrm{PC}$-Card drive, and batter system. The thermal sensitivity is better than $0.08^{\circ} \mathrm{C}$ at $30^{\circ} \mathrm{C}$ and the measurement accuracy is $\pm 2 \%$. The detectors were arranged as a focal plane array with $320 \times 240$ pixels resolution. Image storing is full dynamics with a 14-bit digital storage. The emissivity of the rice canopy was set at 0.98 . The ambient air temperature and relative humidity were measured using a covered and natural wind-aspirated hygrometer (model A2, Rotronic Ag Inc., Swiss) and set at the time of measurements. The radiometer was calibrated from 0 to 500 in Range 2 mode at the laboratory of FLIR with reference blackbodies. Thermograms were analyzed and transformed to radiant temperatures by the ThermaGRAM software provided by FLIR. The software has the statistics functions and the capability of point, line, and area temperatures analyses. Canopy temperatures were calculated from the radiant temperatures of every pixel viewed in the image window.

\section{Results and Discussion}

In Taiwan, climatic factors of air temperature, solar radiation (irradiance), and sunshine hour are in a trend from low to high values following rice plant development in the first cropping season, and vice-versa in the second cropping season (refer to Fig. 1). Such a climate scenario climate affects both growth and yield production of rice grown in different crops (data not shown). The rates of nitrogen uptake, partition and utilization in rice plants are also influenced and may exert additional impacts on growth processes (Lin et al., 1981; Lin \& Chung, 1982).

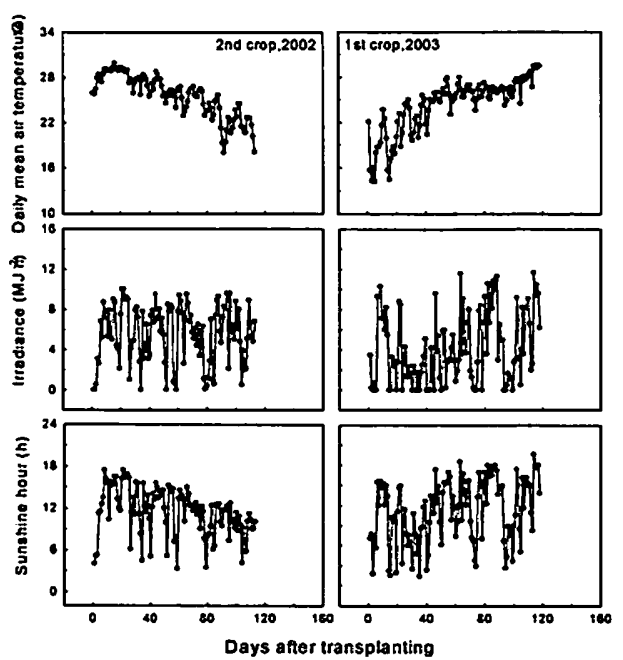

Fig. 1. Changes of climatic factors of daily mean air temperature, irradiance, and sunshine hours during rice (Oryza sativa L. cv. TNG 67) growth in the second cropping season of 2002 and the first cropping season of 2003.

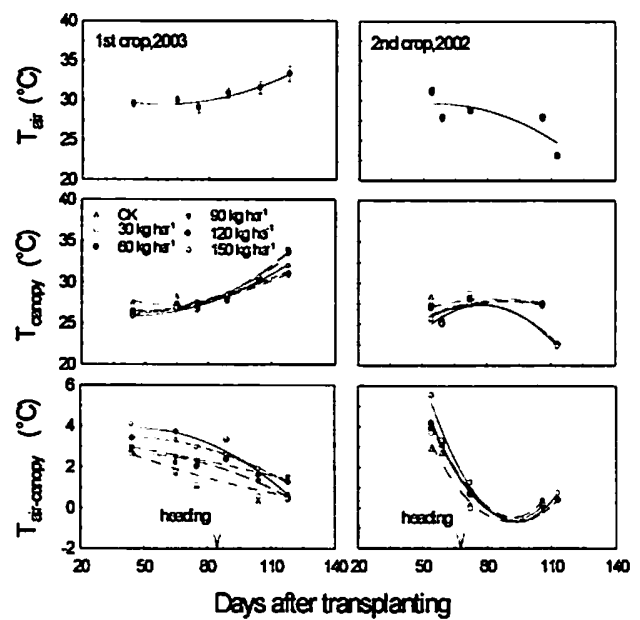

Fig. 2. Changes of ambient air temperature, canopy radiant temperature and temperature difference between ambient air and canopy during rice (Oryza sativa L. cv. TNG 67) growth in the second cropping season of 2002 and the first cropping season of 2003 .

Experimental results showed that canopy radiant temperature corresponded to changes of ambient air temperature during the growing periods in both crops, and this cause-effect relationship affected the trend of temperature differences between the ambient air and rice canopy as plants developed (refer to Fig. 2). Such temperature differences were decreased by the 
increasing of air temperature in the first crop and were decreased by the decreasing of air temperature in the second crop. Under normal growth conditions in the field without moisture limitation, air temperature is generally higher than canopy temperature. In few exceptional cases when the humidity gradient was high and transpiration was in excess, the canopy temperature might be nearly equal air temperature. Similar results have been pointed out by Su \& Yang (1998) and Yang (1999), reporting that the canopy temperature of a rice crop was lower than the ambient air temperature throughout the growing seasons in a well-watered condition. The relationship has been explained by the governing of vapor pressure deficit of the surroundings (Idso et al., 1981) over a large range of vapor pressure, net radiation and wind speed. But the relationship will be changed for a given vapor pressure deficit under water stress (Kanemasu et al., 1985).

There was a tendency for the temperature difference to increase with the increasing rates of nitrogen fertilizer application in both crops, yet no such clear gradient was found near harvest (refer to Fig. 3). When measuring temperatures on the same day, plants with an ample of nitrogen supply would obtain a more vigorous growth than those without sufficient nitrogen nutrient. As there was no restriction in soil moisture, a vigorously growing plant usually acquired more water through acceleration of transpiration rate and produced more chlorophyll to enlarge its photosynthetic capacity for the needs of active growth. Logically, it is not a surprise to observe a lower canopy temperature in plants with higher rates of nitrogen fertilizer than those plants with lower nitrogen rates.

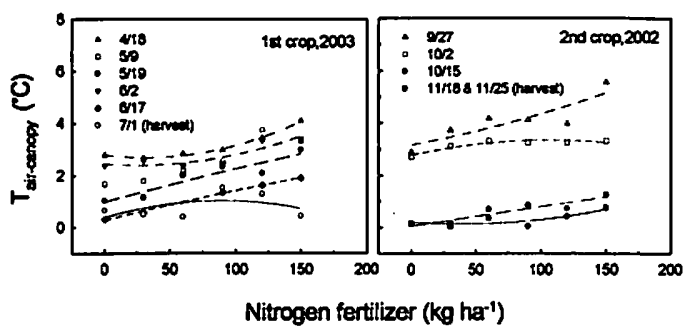

Fig. 3. Correlation between temperature difference between ambient air and canopy and rate of nitrogen fertilizer application for rice plants (Oryza sativa L. cv. TNG 67) grown in the second cropping season of 2002 and the first cropping season of 2003.

When further analyzing temperature difference distributions of rice plants treated with different rates of nitrogen, results indicated that, except near harvest, plants treated with higher nitrogen rates generally showed higher levels of temperature difference distributions (refer to Figs. $4 \mathrm{~A}$ and $4 \mathrm{~B}$ ). Since the phenomenon occurs as early as 44 days after transplanting when background effects become insignificant, analysis of infrared thermograms may provide useful data for preliminary assessment of nitrogen status of a rice crop. With the information as an indication of plant nitrogen state, further investigation can then be conducted for more precise nitrogen measurement and management to select the right place at right time.

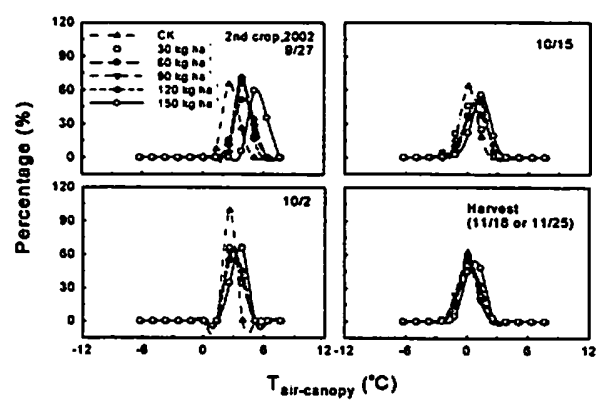

Fig. 4A. The distributions of canopy temperatures measured on different dates from rice plants (Oryza sativa L. cv. TNG 67) treated with different rates of nitrogen fertilizer in the second cropping season of 2002.

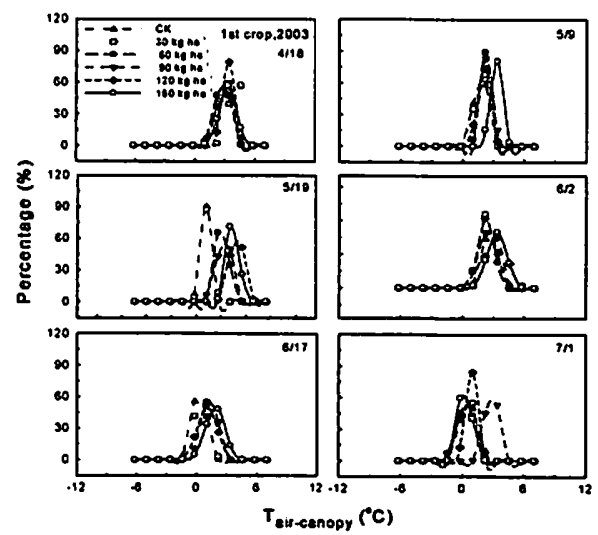

Fig. 4B. The distributions of canopy temperatures measured on different dates from rice plants (Oryza sativa L. cv. TNG 67) treated with different rates of nitrogen fertilizer in the first cropping season of 2003.

This study proves the feasibility and effectiveness of using thermal infrared imagery as a means to measure canopy radiant temperatures and demonstrates the technique as an efficient tool in monitoring delicate and prompt temperature response on the canopy-atmosphere interface. As reported in the literature (Su \& Yang, 1998; Tanner, 1963; Yang, 1994,1998 ), infrared thermograms of a plant canopy provide adequate information for analyses of temperature variation and distribution over the canopy surface. Results further suggest that rice plants are able to regulate transpiration rates to ameliorate temperature fluctuation in the surroundings and to adapt to certain environmental impacts such as varied nitrogen applications.

\section{Acknowledgments}

This work was supported by the Council of Agriculture (93AS-1.1.6-CI-C1), Executive Yuan, Taiwan (ROC).

\section{References}

Berry, J. A., and Raison, J. K., 1981. Response of macrophytes to temperature. In: Encyclopedia of Plant Physiology 12A, Physiological Plant Ecology. l. Response to the physical environment. 
Springer-Verlag, Berlin, pp.277-338.

Clarke, T. R., 1997. An empirical approach for detecting crop water stress using multispectral airborne sensors. Hort Technology, 7(1), 1-16.

Duncan, W. G., and Hesketh, J. D., 1968. Net photosynthetic rates, relative leaf growth rates, and leaf numbers of 22 races of maize grown at eight temperatures. Crop Sci., 8, 670-674.

Erwin, J. E., and Heins, R. D., 1985. The influence of day temperature, night temperature, and photosynthetic photon flux on Lilium longiflorum Thunb. 'Nellie White.' HortScience, 20, 548.

Ellis, R. H., Summerfield, R. J., Edmeades, G. O., and Roberts, E. H., 1992. Photoperiod, temperature, and the interval from sowing to tassel initiation in diverse cultivars of maize. Crop Sci., 32, 1225-1232.

Ellis, R. H., Qi, A., Summerfield, R. J., and Roberts, E. H., 1993. Rates of leaf appearance and panicle development in rice (Oryza sativa L.): a comparison at three temperatures. Agric. For. Meteorol., 66, 129-138.

Fischer, F. J. F., 1954. Effect of temperature on leaf-shape in Ranunculus. Nature, 173, 406-407.

Hatfield, J. L., 1990. Measuring plant stress with an infrared thermometer. HortScience, 25, 1535-1538.

Hodges, T., 1991. Temperature and water stress effects on phenology. In: Predicting Crop Phenology. (ed. Hodges, T.) CRC press, Boca Raton, Florida, pp.7-13.

Idso, S. B., Jackson, R. D., Pinter, Jr., P. J., Reginato, R. J., and Hatfield, J. L., 1981. Normalizing the stress-degree-day parameter for environmental variability. Agric. Meteorol., 24, 45-55.

Jackson, R. D., Reginato, R. J., and Ido, S. B., 1977. Wheat canopy temperature: a practical tool for evaluating water requirements. Water Resour. Res., 65, 651-656.

Kanemasu, E. T., Asrar, G., and Yoshida, M., 1985. Remote sensing techniques for assessing water deficits and modeling crop response. HortScience, 20, 1043-1046.

Kustas, W. P., 1990. Estimates of evapotranspiration with a one- and two-layer model of heat transfer over partial canopy cover. J. Appl. Meteorol., 29, 704-715.

Lee, Y.-J., Yang, C.-M., Su, M.-R., and Fan, M.-J., 1996. Modeling climatic effects on seed germination of soybean. (in Chinese) Chinese Agron. J., 6,229-240.

Lin, H.-C., Chung, R.-S., and Tu, H.-L., 1981. Effect of interaction among temperature regimes, light-climate and nutritional pattern on the development and nutritional physiology of rice plant. II. Influence on uptake, partition and utilization of nitrogen. J. Chinese Agric. Chem. Soc., 19(1-2), 115-124.

Lin, H.-C. and Chung, R.-S., 1982. Empty spikelets of rice as influenced by the interaction of light-climate, temperature and nitrogen nutrition. $J$. Chinese Agric. Chem. Soc., 20(1-2),21-31.

Plant Protection Manual. 2000. Taiwan Agricultural Chemicals and Toxic Substances Research Institute, Wufeng, Taichung Hsien, Taiwan. 791pp.

Robertson, G. W., 1968. A biometeorological time scale for a cereal crop involving day and night temperature and photoperiod. Intl. J. Biometeorol,. 12, 191-223.
Seguin, B., and Itier, B., 1983. Using midday surface temperature to estimate daily evaporation from satellite thermal infrared data. Intl. J. Remote Sens., 4, 371-388.

Su, M.-R., Yang, C.-M., and Lee, Y.-J., 1997. Response of soybean growth to climatic factors in early growing phase. (in Chinese) J. Agric. Assoc. China, 177,86-99.

Su, M.-R., and Yang, C.-M., 1998. Measurement of rice canopy temperature by thermal infrared imagery. (in Chinese) Chinese Agron. J., 8, 29-37.

Tanner, C. B., 1963. Plant temperatures. Agron. J., 55, 210-211.

Thomas, J. F.,and Raper, Jr., C.D., 1978. Effect of day and night temperatures during floral induction on morphology of soybeans. Agron. J., 70, 893-898.

Thomas, J. F., Raper, Jr., C. D., and Weeks, W. W., 1981. Day and night temperature effects on nitrogen and soluble carbohydrate allocation during early reproductive growth in soybeans. Agron. $J$., 73, 577-582.

Throssell, C. S., Carrow, R. N., and Milliken, G. A., 1987. Canopy temperature based irrigation scheduling indices for Kentucky bluegrass turf. Crop Sci., 27, 126-129.

Tollenaar, M., Daynard, T. B., and Hunter, R. B., 1979. Effect of temperature on rate of leaf appearance and flowering date in maize. Crop Sci., 19, 363-366.

Viglierchio, D. R., and Went, F. W., 1957. Plant growth under controlled conditions. IX. Growth and fruiting of the Kentucky Wonder bean (Phaseolus vulgaris). Amer. J. Bot., 44, 449-453.

Watts, W. R., 1971. Role of temperature in the regulation of leaf extension in Zea mays. Nature, 229, 46-47.

Went, F. W., 1944. Plant growth under controlled conditions. II. Thermoperiodicity in growth and fruiting of the tomato. Amer. J. Bot., 31, 135-150.

Yang, C.-M., and Heilman, J. L., 1990. Study of leaf area as functions of age and temperature in rice (Oryza sativa L.). J. Agric. Res. China, 39, 259-268.

Yang, C.-M., 1994. Response of rice yield in relation to solar radiation and air temperature under soil water deficits. Chinese J. Agrometeorol., 1,27-34.

Yang, C.-M., 1997. Applications of spectroradiometry and infrared thermal imagery techniques on agricultural production. (in Chinese) Chinese J. Agrometeorol., 4, 1-10.

Yang, C.-M., 1998. Seasonal changes in radiometric temperature of rice vegetative cover. Chinese Agron. J., 8,193-201.

Yang, C.-M., 1999. Seasonal changes in radiometric temperature of rice vegetation cover. Chinese Agron. J., 8,193-201.

Yang, C.-M., 2003. Remote detection of changes in vertical canopy radiant temperatures for rice plants subjected to water deficits with infrared thermal imagery. J. Agric. Res. China, 52(3), 1-11.

Yin, X., Kropff, M. J., McLaren, G., and Visperas, R.M., 1995. A nonlinear model for crop development as a function of temperature. Agric. For. Meteorol., 77, 1-16. 